Journal of Patient-Centered

4-29-2019

\title{
Suffering in Silence: Is Gastroparesis Underdiagnosed?
}

Dennis J. Baumgardner

Follow this and additional works at: https://aah.org/jpcrr

Part of the Diagnosis Commons, Dietetics and Clinical Nutrition Commons, Digestive System Commons, Digestive System Diseases Commons, Endocrine System Diseases Commons, Gastroenterology Commons, Primary Care Commons, and the Public Health Education and Promotion Commons

\section{Recommended Citation}

Baumgardner DJ. Suffering in silence: Is gastroparesis underdiagnosed? J Patient Cent Res Rev. 2019;6:133-4. doi: 10.17294/2330-0698.1707

Published quarterly by Midwest-based health system Advocate Aurora Health and indexed in PubMed Central, the Journal of Patient-Centered Research and Reviews (JPCRR) is an open access, peer-reviewed medical journal focused on disseminating scholarly works devoted to improving patient-centered care practices, health outcomes, and the patient experience. 


\title{
Suffering in Silence: Is Gastroparesis Underdiagnosed?
}

\author{
Dennis J. Baumgardner, MD | Editor-in-Chief \\ Department of Family Medicine, Aurora UW Medical Group, Aurora Health Care, Milwaukee, WI
}

$\mathrm{I}$ $\mathrm{n}$ this issue of the Journal of Patient-Centered Research and Reviews, we find three articles concerning patients with diabetes mellitus. Homco et al report on implementation of patient-reported outcome measures among type 2 diabetics in two diverse primary care clinics. ${ }^{1}$ Functional limitations, particularly regarding physical function and pain, were identified within this patient population. ${ }^{1}$ Rabaut proposes homedelivered medically tailored meals for type 2 diabetics who are food insecure (ie, "food as medicine"). ${ }^{2}$ And the focus of this editor's message is diabetic gastroparesis, a topic comprehensively reviewed in this issue by a United Kingdom-based authorship group led by gastroenterologist, and JPCRR editor, Adam Farmer. ${ }^{3}$

In introducing their review, Farmer and colleagues comment on the problem of underrecognition of gastroparesis in the diabetic population and the fact that hospitalizations for this entity have been increasing. ${ }^{3} \mathrm{~A}$ recent study also documented an increase in emergency department visits for both nondiabetic and diabetic gastroparesis, the latter increase presumably due to the increase in prevalence of diabetes itself. ${ }^{4}$

As a primary care physician, I wonder how many of these cases we are missing. The literature is not entirely clear. The oft-cited community study of gastroparesis in Minnesota's predominately white Olmstead County (1996-2006) revealed a prevalence of proven diabetic gastroparesis of $0.6 \%$ and of definite, probable, or possible disease of $2.9 \% .{ }^{5}$ Examining a cohort assembled from this same county in the mid-1990s, the cumulative prevalence of gastroparesis was estimated at $5.2 \%$ in type 1 diabetics, $1.0 \%$ in type 2 diabetics, and

Correspondence: Dennis J. Baumgardner, MD, Aurora Sinai Medical Center, 1020 N. 12th Street, \#4180, Milwaukee, WI 53233 (dennis.baumgardner@aurora.org)
$0.2 \%$ in nondiabetic control subjects. ${ }^{6}$ The authors concluded that other causes of upper gastrointestinal symptoms should be sought first in diabetic patients. ${ }^{5,6}$ These authors did note that a previous study reported presence of delayed gastric emptying in diabetic patients of up to $65 \% ;^{7}$ however, it

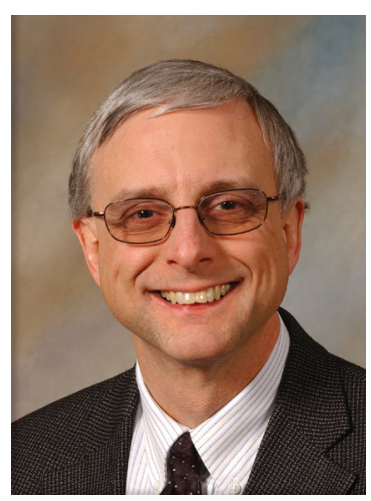
was suggested that because that patient population was pulled from referral centers, such high prevalence was the result of selection bias. ${ }^{5,6}$

Samsom et al reported a $28 \%$ prevalence of delayed gastric emptying among 186 "unselected" diabetic patients; however, this study took place in a university medical center in the Netherlands, which typically manage a higher proportion of complex patients. ${ }^{8}$ Interestingly, it was stated in a recent review article (without cited reference) that gastroparesis "usually occurs 10 years after the onset of diabetes," whereas Samsom et al found no association between the rate of gastric emptying and duration of diabetes in their mixed type $1 /$ type 2 diabetic population. ${ }^{8}$

The concern regarding "missing" gastroparesis cases is not new. Another study conducted in Olmsted was informative. Rey and colleagues performed regression modeling on data from 450 patients referred for a scintigraphic gastric emptying test and a questionnaire mailed to a random sample of county residents. ${ }^{10}$ The estimated prevalence of delayed gastric emptying, based on their model, was $1.8 \%$ in community subjects, a good deal more than their previously calculated prevalence of diagnosed gastroparesis, $0.02 \%{ }^{10}$ Presumably, the estimated community prevalence of gastroparesis would be higher among diabetic patients. 
So, considering the pervasiveness of the problem, what should primary care clinicians do about "missing" diabetic gastroparesis cases in their own patient panels? The first step, of course, is ensuring appropriate documentation when known. This is an issue that goes far beyond this specific disease entity, ${ }^{\text {cf. } 11}$ but there are likely instances in which clinicians may be fully aware of, even treating, gastroparesis in diabetic patients without having overtly documented the condition in the medical record as a separate clinical problem. That is not to say every patient with some degree of delayed gastric emptying merits a gastroparesis diagnosis, as a significant number of patients with confirmed delayed gastric emptying have no or minimal symptoms. ${ }^{8}$ From a clinical perspective, we are much less concerned about these individuals. In fact, it would not be appropriate to "create a disease state" for those patients not bothered by delayed gastric emptying.

What we do wish to prevent is overlooking the patient who is suffering with gastroparesis symptoms in silence, not only for their symptomatic well-being but also to better inform any diagnostic or treatment conundrums, such as pseudodyslipidemia caused by an artificial increase in lipid levels resulting from delayed gastric emptying. ${ }^{12}$

Potentially, neither the diabetic patient nor the clinician may present or inquire about gastroparesis symptoms, particularly in the common ambulatory clinical setting of 10-20-minute visits, multiple problems to address besides diabetes, ${ }^{11}$ and standard office testing and health metrics screenings. In all this tangle, system reviews may become rote (ie, electronic "box checking") and time for extra discussion limited.

In addition, gastrointestinal complaints may indeed stem from (or be assumed to stem from) some other more common cause or be confused with gastrointestinal symptoms from a common diabetic medication like metformin. There may be other explanation for similar symptoms. For example, bloating, usually with later diarrhea, may be caused (unbeknownst to both patient and clinician) by the sorbitol or other polyalcohol sugars in some artificially sweetened products. ${ }^{13}$ (I learned this, in part, from my diabetic father who learned to "treat" his episodic constipation with his sugar-free candies or cough drops.) Patients themselves can make assumptions regarding the etiology of their gastroparesis symptoms and therefore not bring them up in clinical settings.

As challenging, yet simple, as doing so may be, clinicians must query diabetic patients regarding nausea and vomiting, early satiety, and bloating. If these symptoms emerge, effective diagnosis and treatment, as discussed by Farmer and colleagues, ${ }^{3}$ may be undertaken to alleviate diabetic gastroparesis in our patients. Perhaps then they will be able to better enjoy their medically tailored meals. ${ }^{2}$

\section{References}

1. Homco J, Rodriguez K, Bardach DR, et al. Variation and change over time in PROMIS 29 survey results among primary care patients with type 2 diabetes. J Patient Cent Res Rev. 2019;6:135-47.

2. Rabaut LJ. Medically tailored meals as a prescription for foodinsecure type 2 diabetics. J Patient Cent Res Rev. 2019;6:179-83.

3. Farmer AD, Bruckner-Holt CE, Schwartz S, Sadler E, Kadirkamanthan S. Diabetic gastroparesis: perspectives from a patient and health care providers. J Patient Cent Res Rev. 2019;6:148-57.

4. Hirsch W, Nee J, Ballou S, et al. Emergency department burden of gastroparesis in the United States, 2006 to 2013. $J$ Clin Gastroenterol. 2019;53:109-13. CrossRef

5. Jung HK, Choung RS, Locke GR 3rd, et al. The incidence, prevalence, and outcomes of patients with gastroparesis in Olmsted County, Minnesota, from 1996 to 2006. Gastroenterology. 2009;136:1225-33. CrossRef

6. Choung RS, Locke GR 3rd, Schleck CD, Zinsmeister AR, Melton LJ 3rd, Talley NJ. Risk of gastroparesis in subjects with type 1 and 2 diabetes in the general population. Am J Gastroenterol. 2012;107:82-8.

7. Jones KL, Russo A, Stevens JE, Wishart JM, Berry MK, Horowitz M. Predictors of delayed gastric emptying in diabetes. Diabetes Care. 2001;24:1264-9. CrossRef

8. Samsom M, Vermeijden JR, Smout AJ, et al. Prevalence of delayed gastric emptying in diabetic patients and relationship to dyspeptic symptoms: a prospective study in unselected diabetic patients. Diabetes Care. 2003;26:3116-22. CrossRef

9. Shen S, Xu J, Lamm V, Vachaparambil CT, Chen H, Cai Q. Diabetic gastroparesis and nondiabetic gastroparesis. Gastrointest Endosc Clin N Am. 2019;29:15-25. CrossRef

10. Rey E, Choung RS, Schleck CD, Zinsmeister AR, Talley NJ, Locke GR 3rd. Prevalence of hidden gastroparesis in the community: the gastroparesis "iceberg." J Neurogastroenterol Motil. 2012;18:34-42. CrossRef

11. Beasley JW, Hankey TH, Erickson R, et al. How many problems do family physicians manage at each encounter? A WReN study. Ann Fam Med. 2004;2:405-10. CrossRef

12. Adar T, Lysy J. Pseudodyslipidemia: are we over-treating dyslipidemia in diabetic patients with undiagnosed gastroparesis? Endocrine. 2014;45:26-7. CrossRef

13. Bauditz J, Norman K, Biering H, Lochs H, Pirlich M. Severe weight loss caused by chewing gum. BMJ. 2008;336:96-7. CrossRef

(C) 2019 Aurora Health Care, Inc. 